University of Nebraska - Lincoln

DigitalCommons@University of Nebraska - Lincoln

USDA Forest Service / UNL Faculty Publications U.S. Department of Agriculture: Forest Service -National Agroforestry Center

$12-2008$

\title{
Characterizing Forest Fragments in Boreal, Temperate, and Tropical Ecosystems
}

\author{
Arjan J. H. Meddens \\ University of Idaho, arjan.meddens@vandals.uidaho.edu \\ Andrew T. Hudak \\ Rocky Mountain Research Station, ahudak@fs.fed.us \\ Jeffrey S. Evans \\ USDA Forest Service, Rocky Mountain Research Station, jevans02@fs.fed.us \\ William A. Gould \\ International Institute of Tropical Forestry GIS and Remote Sensing Laboratory,wgould@fs.fed.us \\ Grizelle Gonzalez \\ USDA Forest Service, International Institute of Tropical Forestry, ggonzalez@fs.fed.us
}

Follow this and additional works at: https://digitalcommons.unl.edu/usdafsfacpub

Meddens, Arjan J. H.; Hudak, Andrew T.; Evans, Jeffrey S.; Gould, William A.; and Gonzalez, Grizelle, "Characterizing Forest Fragments in Boreal, Temperate, and Tropical Ecosystems" (2008). USDA Forest Service / UNL Faculty Publications. 174.

https://digitalcommons.unl.edu/usdafsfacpub/174

This Article is brought to you for free and open access by the U.S. Department of Agriculture: Forest Service -National Agroforestry Center at DigitalCommons@University of Nebraska - Lincoln. It has been accepted for inclusion in USDA Forest Service / UNL Faculty Publications by an authorized administrator of DigitalCommons@University of Nebraska - Lincoln. 


\section{Characterizing Forest Fragments in Boreal, Temperate, and Tropical Ecosystems}

An increased ability to analyze landscapes in a spatial manner through the use of remote sensing leads to improved capabilities for quantifying human-induced forest fragmentation. Developments of spatially explicit methods in landscape analyses are emerging. In this paper, the image delineation software program eCognition and the spatial pattern analysis program FRAGSTATS were used to quantify patterns of forest fragments on six landscapes across three different climatic regions characterized by different moisture regimes and different influences of human pressure. Our results support the idea that landscapes with higher road and population density are more fragmented; however, there are other, equally influential factors contributing to fragmentation, such as moisture regime, historic land use, and fire dynamics. Our method provided an objective means to characterize landscapes and assess patterns of forest fragments across different forested ecosystems by addressing the limitations of pixel-based classification and incorporating image objects.

\section{INTRODUCTION}

Forest fragmentation is induced by human activities and natural processes. Human-induced fragmentation increases ecosystem vulnerability toward fire, the threat of invasive species, and habitat decline (1). Forest fragmentation can be defined as the breaking up of a forested unit, where the number of patches and the amount of exposed edge increase while the amount of core area decreases (2), whereby core area is defined as a forested area free of edge effects (3). The size and shape of forest fragments are strongly dependent on terrain characteristics. For instance, roads in mountainous landscapes tend to follow topographic contours and resemble stream networks, while in flat terrain, road networks often exhibit systematic gridded patterns. Anthropogenic factors that have been welldescribed in recent literature and that affect forest fragmentation include roads (4), agriculture (5), forest logging practices (6), and urbanization (7).

Although forest fragmentation has serious implications for biodiversity loss and habitat decline $(8,9)$, another serious issue involves fire. The effects of fragmentation and fire dynamics are often intertwined. High densities of roads increase fire danger by drying forests along edges, altering fuel loads, and providing access to humans who ignite fires (10). Forest logging is often accompanied with increased road density, influencing both moisture regimes and the initiation of repeating fire cycles in formerly unburned forests (11).

Recently, developments in the field of remote sensing have increased the use of spatially explicit landscape analyses. Moderate-resolution satellite imagery, primarily Landsat, can be broadly applied for analyses of landscape patterns (12). Studies of the process of landscape fragmentation rely predominantly on land-cover classification derived from Landsat imagery (13). Landsat images are often preferred over other moderate-resolution multispectral satellite imagery because they have been available globally since 1972, and they also possess a $30 \mathrm{~m}$ pixel size that can resolve most changes in land use or land cover.

Traditional image classification algorithms operate at the level of a single pixel, ignoring the surrounding pixels; this results in classification units of only one pixel in size, which constitute noise for an analyst interested in landscape pattern or a manager desiring management units of a useful minimum size. Object-oriented methods for landscape classification and analyses have been found to exceed accuracies of traditional spectral classification methods that treat each pixel independently (14-16). Object-oriented image segmentation algorithms such as Fractal Net Evolution (17), available in the software eCognition (18), consider both spectral and contextual information to partition pixels into discrete image objects more representative of landscape pattern. Image segmentation aims to minimize variability within image objects while maximizing variability between image objects. This effectively describes the means by which an aerial photo interpreter delineates forest stands into management units. As such, automated objectoriented image segmentation, or the partitioning of similar image pixels into landscape units (polygons), has potential to replace slower and more subjective manual aerial photo interpretation and stand delineation techniques.

Software programs such as FRAGSTATS have been widely applied to calculate patch, class, and landscape metrics from classified data layers (19). Landscape metrics have been used to compare different landscape patterns (20) and to establish relationships between ecological processes and individual species (21). Appropriate caution must be exercised not to use too many metrics (which number in the hundreds) without recognizing and accounting for the high degree of redundancy among them $(4,22)$.

The aforementioned developments in satellite remote sensing (e.g., Landsat), digital image processing (e.g., eCognition), and geographic analysis techniques (e.g., FRAGSTATS) are facilitating spatially explicit consideration of landscape patterns and processes. A single image represents a mere snapshot of fragmentation (or any landscape process) in time, but much about a landscape process may be inferred by landscape pattern (1). Fragmentation can proceed slowly, or over longer time scales than the available images record. A comparison of several landscapes representing various stages of fragmentation along a spatial chronosequence provides a useful means to quantify and better understand fragmentation effects on landscapes in general.

In this paper, we assess forest fragmentation in six forested landscapes representing varying degrees of fragmentation located in boreal, temperate, and tropical forests in North America and the Caribbean. We hypothesize that landscapes that have higher population density and more roads are more fragmented. Our goal is to demonstrate that remotely sensed data, image segmentation, and landscape analysis tools can be a used in a consistent manner to characterize and compare fragmented forest landscapes across boreal, temperate, and tropical forest ecosystems in North America and the Caribbean. 


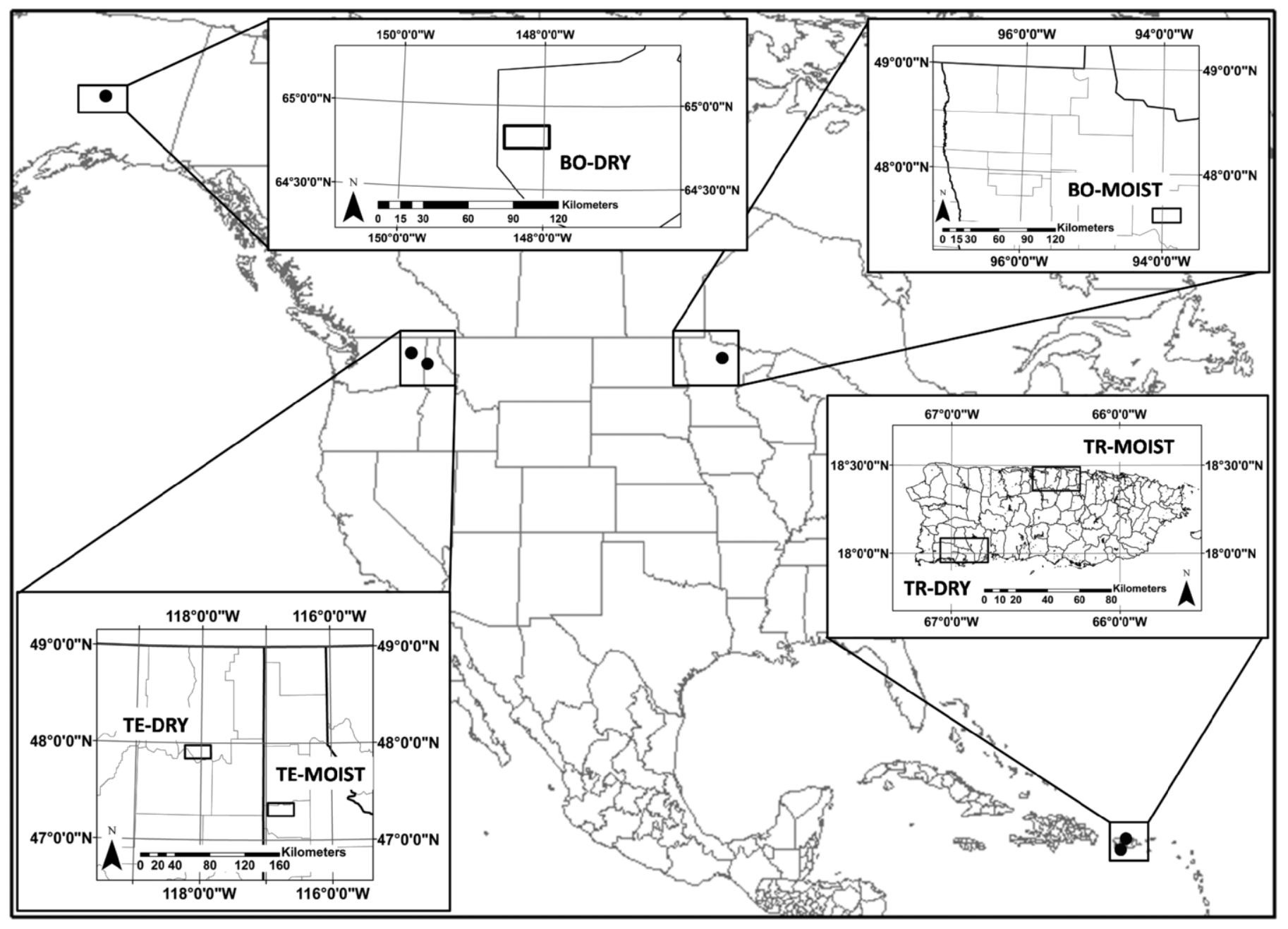

Figure 1. Study area locations (rectangles); BO-DRY in Alaska, BO-MOIST in Minnesota, TE-DRY in Washington, TE-MOIST in Idaho, and TRDRY and TR-MOIST in Puerto Rico.

\section{METHODS}

\section{Study Area Descriptions}

The six study areas (Fig. 1) analyzed in this study contrast high population densities in tropical forest with much lower population densities in temperate and boreal forests (Table 1). The six selected study areas were selected to be approximately the same size ( $\sim 45000$ ha) and to represent dry and moist boreal (Alaska and Minnesota), temperate (Washington and Idaho), and tropical (Puerto Rico) forest types. These study areas were selected for permission and practicality of access as well as the availability of field data to validate the edge location of forest fragments. For purposes of this study, we assumed them to be representative of the six forest types sampled.

The dry boreal forest area (BO-DRY) is located in eastern interior Alaska on Bureau of Land Management (BLM) land, while the moist boreal forest (BO-MOIST) is located in north central Minnesota in the Chippewa National Forest. The BODRY area is more coniferous than deciduous and interspersed by rivers, while the BO-MOIST area is more deciduous than coniferous and more interspersed by lakes. Both temperate areas occurred in coniferous forests on Native American Tribal lands in the Interior Northwest: the TE-DRY area is located in the Spokane Indian reservation in eastern Washington, while the TE-MOIST area is located in the Coeur d'Alene Indian Reservation in northern Idaho. The TE-DRY area is dominated by Pinus ponderosa (ponderosa pine) and, on moister aspects, Pseudotsuga menziesii (Douglas fir), while the TE-MOIST area is a more species-rich mixed conifer forest. Both tropical forest areas in Puerto Rico, TR-DRY and TR-MOIST, occur mainly on private land. The TR-DRY area is located in southwestern Puerto Rico and encompasses the Guánica Dry Forest Reserve and has relatively high tree species diversity. The TR-MOIST area occurs in the heavily populated northern coastal plain of Puerto Rico, west of the San Juan Metropolitan area. Importantly, dry forests have a more open canopy structure than moist forests in all three climate regions (23). The terrain is mainly flat in the two boreal landscapes, while it is generally hilly in the two temperate and two tropical landscapes.

Forest patterns in the BO-DRY area have been fragmented mostly by historic fires and less by human activities, with relatively few settlements, roads, or logging. The BO-MOIST area has been more fragmented by settlements, roads, logging, and agriculture than by historic fires. Prescribed fires also have fragmented forests in the TE-DRY area, as have logging, roads, and settlements. The TE-MOIST area similarly has been impacted by logging, roads, and settlements, with agriculture an added factor. Both the TR-DRY and TR-MOIST areas have been heavily fragmented due to high population densities, contributing to widespread urbanization, dense road networks, and intensive agriculture.

\section{Field Data}

In 2002 and 2003, field campaigns were conducted in Puerto Rico, Washington, Idaho, Minnesota, and Alaska to measure canopy and ground fuels along forest edge gradients. Forest edges caused by roads, timber harvest, agriculture, or urban- 


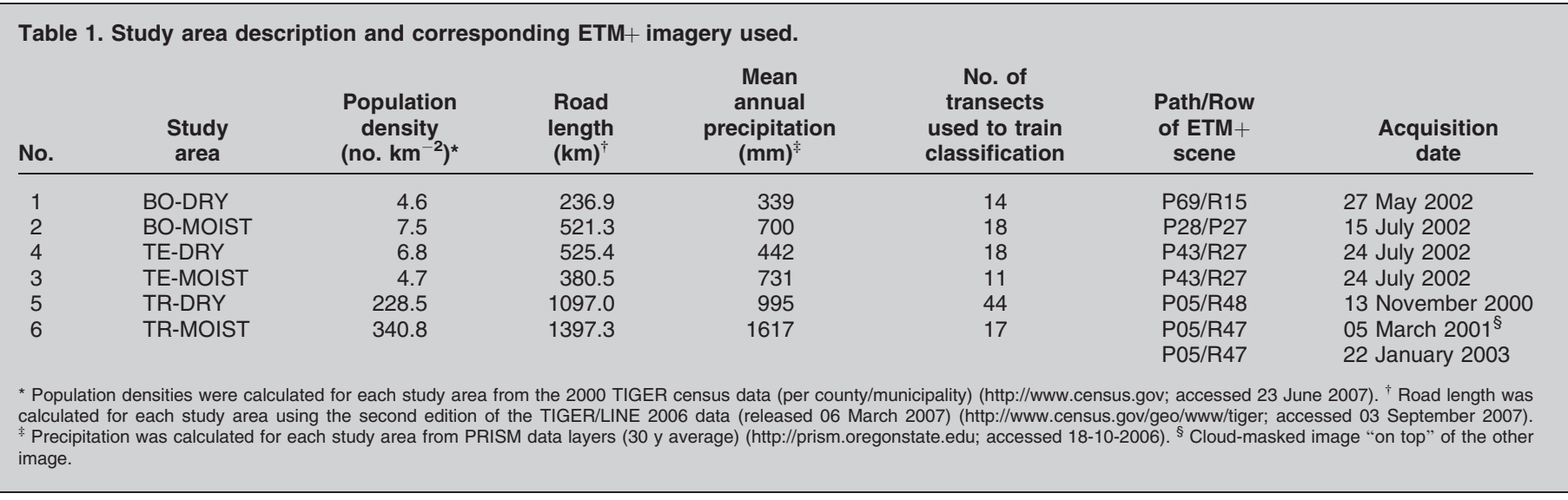

ization were sampled in the field across the full range of forest structure types observed in each study landscape. A forest edge was defined as a distinct nonforest-forest transition as observed in the field, rather than a priori in a Landsat image. Thus, edges were selected in the field somewhat subjectively but in a manner that could not have biased the ability to detect the edges from Landsat data. This was because the scale of a forest edge is finer than that of $30 \mathrm{~m}$ Landsat pixels, or $15 \mathrm{~m}$ in the case of fused pixels (i.e., fused by combining the $30 \mathrm{~m}$ multispectral bands with the $15 \mathrm{~m}$ panchromatic band), as were used in this study. Therefore, the position of a point along an irregular forest edge selected for sampling was necessarily independent of its position within the regular Landsat raster image grid encompassing that edge.

At each field site, forest canopy and ground fuels were measured using standard forestry techniques at five variableradius plots systematically located along a $60 \mathrm{~m}$ linear transect oriented perpendicular to the forest edge (Fig. 2). Each transect consisted of a nonforest plot centered $5 \mathrm{~m}$ outside the forest edge, an edge plot centered $5 \mathrm{~m}$ inside the forest edge, and three forest (interior) plots 15,35 , and $55 \mathrm{~m}$ inside the forest edge (see Table 1 for the number of transects used for each study area). Horizontal distances between plots along a transect were measured with a laser rangefinder with slope correction. The centers of the outermost (nonforest) and innermost plots of each transect were geolocated by logging at least 100 static positions with a Trimble ProXR geographic positioning system (GPS), and these positions were subsequently differentially corrected using Pathfinder Office v2.9 with a geolocational error of $<1 \mathrm{~m}$. The canopy and ground fuel values were measured for other purposes and are inconsequential for this paper, but the plot location data were used to train the image classification of the landscapes into forested and nonforested classes, as will be described in a subsequent section.

\section{Image Preprocessing}

The TE-DRY and TE-MOIST areas were situated within the same Landsat Enhanced Thematic Mapper (ETM+) scene, while the BO-DRY area in Alaska and BO-MOIST area in Minnesota were necessarily in separate scenes. Therefore, it was necessary to correct for solar illumination angles and atmospheric conditions, which differ between scenes. For consistency, the same correction techniques were applied to all scenes (Table 1).

The authors developed code in ERDAS IMAGINE Spatial Modeler Language (SML) to atmospherically correct images using the cost-correction model developed by Chavez (24) with dark object subtraction, converting digital numbers into atsensor reflectance and minimizing atmospheric effects. An adaptive image model, based on the method proposed by
Steinnocher (25), was written by the authors using SML, which fused the six $30 \mathrm{~m}$ reflectance bands with the $15 \mathrm{~m}$ panchromatic band and thus enhanced edges without significantly changing spectral values. All images were converted to their corresponding UTM zone and the NAD83 projection. We found the enhanced spatial accuracy of the National Landsat Archive Production System (NLAPS)-processed Landsat imagery that we used greatly minimized image registration error. Finally, the full scenes were subset to an $\sim 45000$ ha area surrounding the field transect locations.

In the tropical landscapes, we utilized a $15 \mathrm{~m}$ fused Landsat ETM+ "cloud-free" mosaic that was recently produced for the entirety of Puerto Rico (26). While phenological variation is slight in the tropical landscapes, due attention was given to selecting scenes for the mosaic from approximately the same season (Table 1). Unfortunately, cloud-free imagery could not be found for some mountainous localities, so cloud and cloud shadow masks were applied to give the appearance of a cloudfree mosaic. These images for both the TR-DRY and TRMOIST areas were converted from radiance to reflectance values. They then were fused with the panchromatic band to obtain the enhanced resolution of $15 \mathrm{~m}$, as in the boreal and

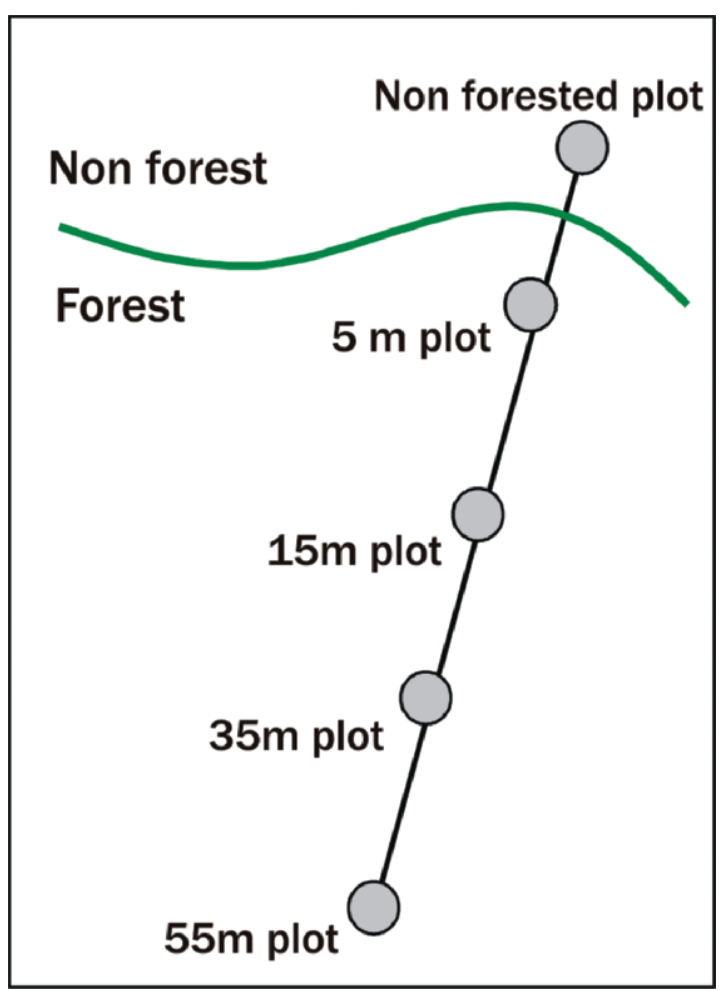

Figure 2. Illustration of a field transect. 


\section{Boxplots of image object sizes}

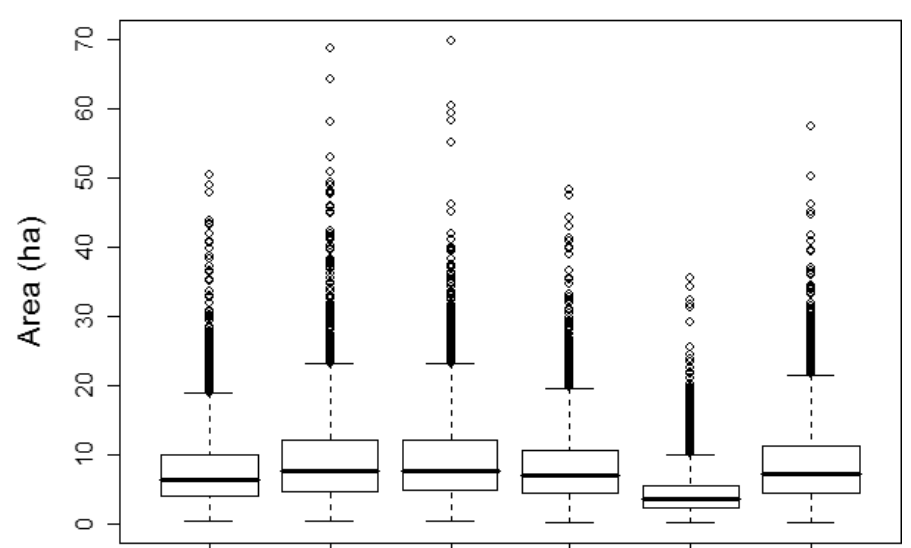

BO-DRY BO-MOIST TE-DRY TE-MOIST TR-DRY TR-MOIST

Study area

Figure 3. Box plots of the forested eCognition image object sizes per study area.

temperate areas. See Martinuzzi et al. (26) for the complete image-processing procedures used to produce the Puerto Rico "cloud-free" mosaic.

\section{eCognition}

For each study site, the six $15 \mathrm{~m}$ fused ETM+ reflectance bands were passed to the eCognition multiresolution image segmentation algorithm to delineate the spatial data into polygons with similar spectral values. The algorithm assembles spectrally similar and spatially adjacent pixels into image objects, or in other words, combines pixels that minimize pixel variability within groups and maximize pixel variability between groups (17). The parameters used to employ the algorithm were taken from a companion study (27) and were set with a 0.2 shape parameter and a 20 form factor, with all other parameters left as the defaults (18).

Figure 3 shows the box plots of the image object sizes. The mean object image sizes are between 4.3 ha (TR-DRY) and 9.4 ha (TE-DRY), which are realistic sizes for forested landscape elements. For example, Gustafson and Crow (28) reported an average forest stand size of 9 ha, and Siegert and McCullough (29) report areas between 1.2 and 22.8 ha of pine stands in the Midwestern US. The large image objects shown in Figure 3 are indicative of homogeneous closed forest canopy. We assumed that the image objects generated by eCognition represented landscape units that were indicative of forest pattern at the time of the image acquisition.

\section{Classification}

The six reflectance bands were reduced into three using the tasseled cap transformation (30) to eliminate redundant spectral information and improve classification accuracy (see also Fig. 4 for explanation). After applying the tasseled cap transformation, the images were classified using the supervised maximum likelihood method in ERDAS IMAGINE. Pixels corresponding to the forested plot locations $15 \mathrm{~m}, 35 \mathrm{~m}$, and $55 \mathrm{~m}$ inside the forest edge were used to train the forest class, while pixels from the nonforested plots $5 \mathrm{~m}$ outside the forest edge were used to train the nonforest class. The edge plot pixels $5 \mathrm{~m}$ inside the forest edge were excluded because they could occur in the same $15 \mathrm{~m}$ pixel as the nonforest plots, and we wanted to define the forested class more conservatively because only the forested class would be subsequently analyzed. In addition, an urban/ bare ground class and a water class were added to the supervised classification where obviously present, and in the case of the TR-MOIST and TR-DRY study areas, the cloud and cloud shadows were set to "no data." After classification, the categories were reclassified as forest, nonforest (including agricultural and urban areas), water, and "no data" (clouds and cloud-shadows in the TR-DRY and TR-MOIST area). Next, the reclassified image was overlaid with the eCognition delineated image object polygon layer to classify polygons according to the majority (mode) of the classified pixels occurring within each polygon (Fig. 5). In other words, if the majority of pixels within a delineated polygon were classified as forest, then the whole polygon was classified as forest, and if the majority of pixels were classified as nonforest, then the whole polygon was classified as nonforest.

\section{Landscape Metrics and Analyses}

FRAGSTATS calculates metrics at three different hierarchical levels: landscape, class, and patch (19). The landscape level includes all of the patches within a defined landscape and was used here to characterize the study areas as a whole. The class level metrics mainly involve differences between classes; since the focus of this study was only on the forested class, no class metrics were evaluated. The patch-level metrics were calculated on the individual patches within each class, in this case, just the forested class, providing a distribution of values for these metrics that could be statistically compared among study areas.

We selected several landscape-level metrics: total area (TA) of land (excluding water, clouds, or cloud shadows), forested

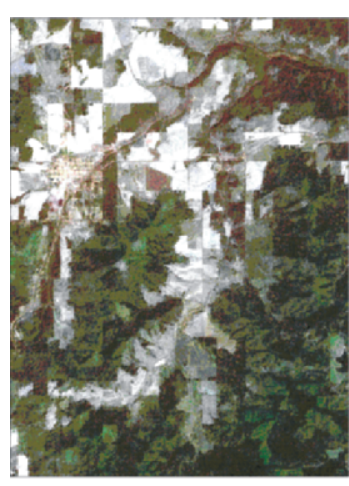

a.

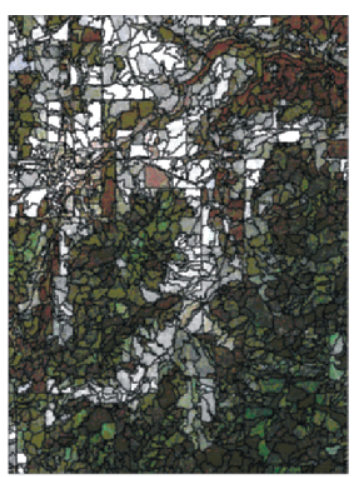

b.

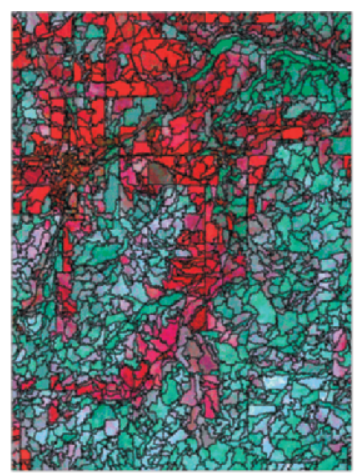

C.
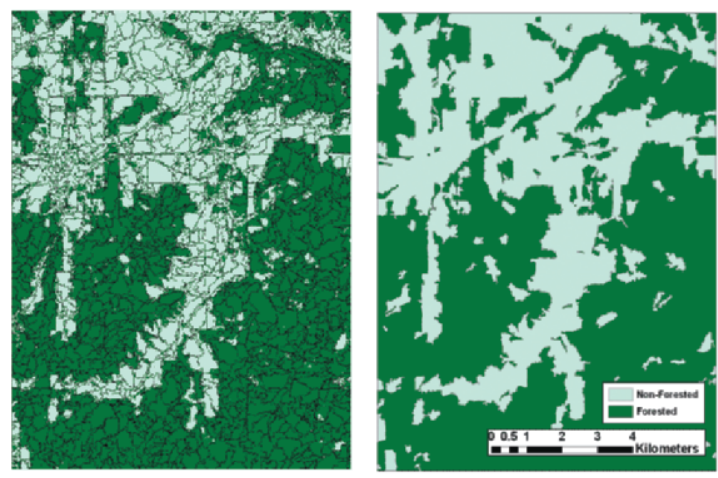

d.

e.

Figure 4. Illustration of an image segmentation and classification. (a) Subset of the TE-MOIST Landsat ETM+ image. (b) Landsat ETM+ image with delineated polygon layer. (c) Tasseled cap transformed image with delineated polygon layer. (d) Pixel-based maximum likelihood classified image. (e) Classified image according to the majority of the forested pixels inside each polygon. 


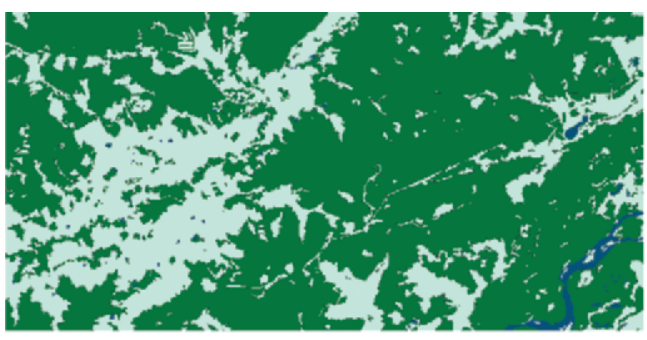

a.

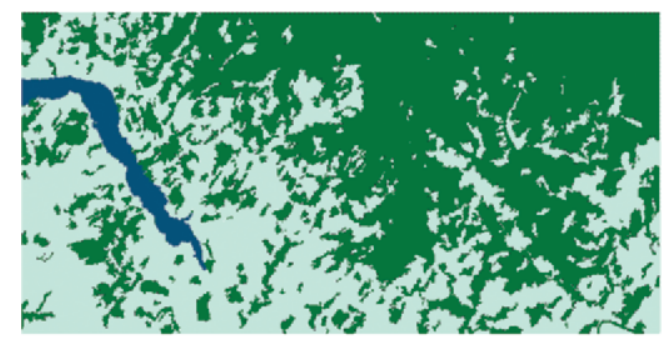

C.

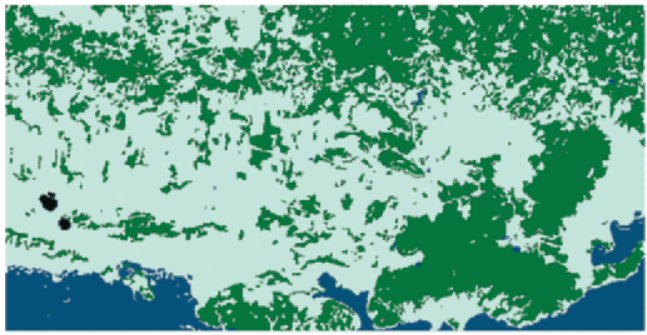

e.

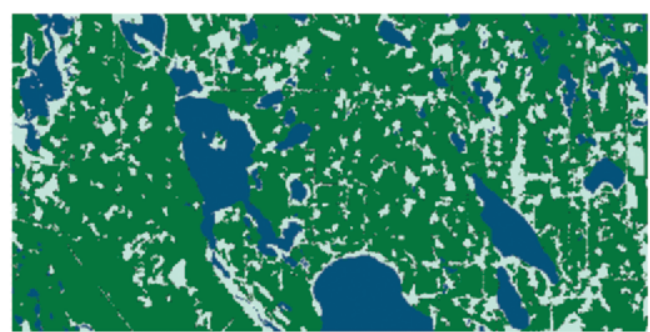

b.

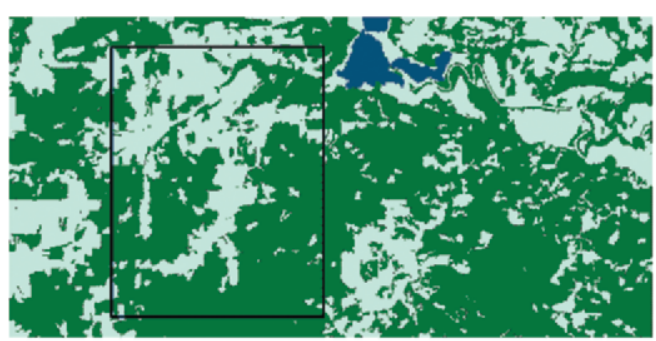

d.
Figure 5. Six maps of the classified study areas. (a): BO-DRY, (b) BOMOIST, (c) TE-DRY, (d) TE-MOIST, (e) TR-DRY, (f) TR-MOIST. (The frame in map d shows the extent of Figure 4.)

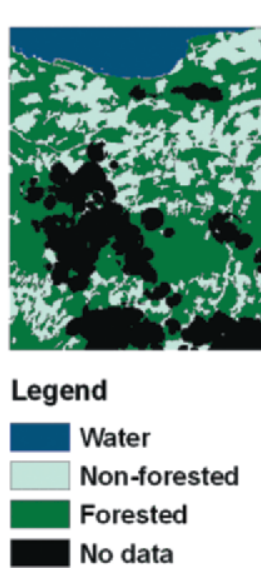

area (FA), percentage forested (PFOR), number of patches (NP), patch density (PD), total edge (TE), and relative edge length (REL) (Table 2). These metrics were chosen because they have little redundancy among them yet have intuitive ecological meaning. The four patch-level metrics included: mean patch area (MPA), perimeter area ratio (PAR), proximity index (PROX), and core area of the forested patches (CORE). The distributions of the patch-level metrics (dependent variables) were analyzed using a one-way analysis of variance (ANOVA) with the nonparametric Kruskal-Wallis chi-square test (31), which indicates significant differences between the means of the patch-level metrics by study area (grouping variable). In addition, the Spearman's rank correlation coefficient $(\rho)$ was calculated between some of the landscape-level metrics and the population density and the road length $(n=6)$ per study area (Table 1). R software was used for all statistical analyses (32).

The landscape-level and class-level metrics were calculated with FRAGSTATS based on effective areas, i.e., $\sim 45000$ ha less those areas classified as water (all six study areas), or as "no data" due to cloud or cloud shadow masks (TR-DRY and TRMOIST areas). FRAGSTATS was instructed to ignore the outer edge of the study area, and polygons adjacent to the water class or to the "no data" masks in order to prevent these factors from confounding the analysis. This is because the study area boundaries and the position of the cloud or cloud shadow masks have little relationship to features on the ground, yet they can alter the size and shape of adjacent polygons in the imagery and, consequently, any calculated metrics. Although water is a real landscape feature, its effect on adjacent polygon characteristics is not a function of human-induced changes, as are the urban or agricultural areas of land-use conversion of primary interest. In summary, only those forested polygons not touching the study area boundaries, water features, or "no data" masks were included in the results.

\section{RESULTS}

\section{Landscape-Level Metrics}

The percentage forested (PFOR) was highest in the boreal region, lowest in the tropical region, and intermediate in the temperate region (Table 3 ). PFOR was significantly negatively correlated with road length $(\rho=-0.89, \mathrm{p}=0.03)$, and PFOR showed a negative but insignificant tendency toward population density $(\rho=-0.77, \mathrm{p}=0.10)$. There were differences in PFOR between the dry and moist landscapes in the temperate and tropical regions; lower PFOR was found in the dry landscapes. However the difference in PFOR between the BO-DRY and BO-MOIST areas was only slight.

The number of patches (NP) was highest in the TR-DRY area and lowest in the BO-MOIST area. The NP was large in the tropical areas, and, along with a lower PFOR, it suggests a higher degree of fragmentation relative to the nontropical study areas (Table 3). Neither NP nor patch density (PD) was significantly correlated with population density $(\rho=0.43, \mathrm{p}=$ 0.42 and $\rho=0.43, \mathrm{p}=0.42$ for NP and PD, respectively) or road length $(\rho=0.54, \mathrm{p}=0.30$ and $\rho=0.54, \mathrm{p}=0.30$ for NP and PD, respectively). When considering the PFOR and NP results together, it is apparent that the dry areas across all climatic regions have more patches compared to their moist study area counterparts in the same region. This is also apparent in the patch density metric (PD), which shows the same pattern: higher for the dry areas, lower for the moist areas. 
Table 2. Description of the FRAGSTATS metrics employed.

\begin{tabular}{|c|c|c|}
\hline Metric & $\begin{array}{l}\text { Formula } \\
\text { (units) }\end{array}$ & Description \\
\hline PFOR & $\frac{F A}{T A}(\%)$ & Percentage forested \\
\hline NP & (unitless) & Number of forested patches \\
\hline PD & $\begin{array}{l}\frac{N P}{T A}\left(\mathrm{ha}^{-1}\right) \\
N P\end{array}$ & $\begin{array}{l}\text { Density of forested patches (number per } \\
100 \text { ha) }\end{array}$ \\
\hline TE & $\sum_{1} e(\mathrm{~km})$ & $\begin{array}{l}\text { Total edge length of the forested } \\
\text { patches }\end{array}$ \\
\hline REL & $\frac{T E}{P F O R}$ (unitless) & $\begin{array}{l}\text { Relative edge length; the total edge } \\
\text { length corrected for the fraction of the } \\
\text { total forested area }\end{array}$ \\
\hline MPS & (ha) & Mean patch size of the forested patches \\
\hline PAR & $\frac{p}{a}$ (unitless) & $\begin{array}{l}\text { Perimeter area ratio of the forested } \\
\text { patches }\end{array}$ \\
\hline CORE & (ha) & $\begin{array}{l}\text { Core area of the forested patches } \\
\quad(\text { search radius }=100 \mathrm{~m})\end{array}$ \\
\hline PROX & $\sum_{1}^{N T} \frac{a}{h}$ (unitless) & $\begin{array}{l}\text { Proximity index of the forested patches } \\
\text { with specified neighborhood of } 100 \mathrm{~m}\end{array}$ \\
\hline
\end{tabular}

$F A=$ total forested area; $T A=$ total area (excluding background); $e=$ edge length of patch; $p=$ perimeter of patch; $a=$ area of patch; $h=$ distance between two patches based on edge-to-edge distance.

Total edge (TE) represents a measure for the actual forestnonforest edge length (excluding the study area border, water, and "no data" edges), while the relative edge length (REL) is more informative when comparing the different study landscapes because it is corrected for the forested fraction. We found that the REL is higher in the drier landscapes of the temperate and the tropical regions but lower in the drier landscape of the boreal region (Table 3). The TE length had no apparent relationship with population density $(\rho=0.09, \mathrm{p}=0.92)$ or road length $(\rho=-0.03, \mathrm{p}=1.0)$, whereas the REL showed a positive yet insignificant tendency toward population density $(\rho=0.71$, $\mathrm{p}=0.14)$ and road length $(\rho=0.83, \mathrm{p}=0.06)$.

\section{Patch-Level Metrics}

Three patch-level metrics, the mean patch area (MPA), the perimeter area ratio (PAR), and the proximity index (PROX), show highly significant $(\mathrm{p}<0.001)$ differences between study areas, while the CORE patch-level metric was insignificant ( $\mathrm{p}=$ 0.095) (Table 3). The MPA is higher for the moist areas compared to their corresponding dry areas in the same climatic zone. In addition, the MPA is higher in the boreal region than in the temperate region, which in turn is higher than in the tropical region. The shape index (PAR) shows that shape complexity is highest in the two boreal areas and lowest in the
TE-DRY area. The proximity index (PROX) shows similar trends as the MPA, with primarily lower values for drier areas, and an increasing trend with increasing latitude. There were no significant differences between the core areas (CORE). While the mean values show a similar pattern as the MPA, there is great variability within the study sites and therefore no significant difference in the CORE metric.

\section{DISCUSSION}

It was difficult to detect significant trends in the landscape-level metrics based on only six study areas. On the other hand, it was easy to detect significant trends in the patch-level metrics, because hundreds of patches were generated per study area. Thus, we interpret the slightly insignificant results in the landscape-level metrics to have potential ecological significance that may merit further study, such as the negative but insignificant $(p>0.05)$ relationship we found between PFOR and population density.

Our image analysis approach was repeated in identical fashion over each landscape, allowing us to characterize the extent and nature of forest fragments, as represented by consistently derived image objects, between the selected study areas. We caution that the image objects generated by eCognition represent landscape units at the point in time the Landsat image was acquired and may not accurately indicate the true nature of the fragmentation process that has been ongoing for decades. We further caution that our six selected study areas may not represent the average degree of forest fragmentation across the dry and moist tropical, temperate, and boreal forest types. These two cautions concern a temporal and spatial scope of inference that was well beyond our ability to address. However, we do believe our analysis approach has merit as a means to objectively and consistently characterize fragmented forest landscapes.

Our results support the idea that high road density and human population density is correlated with greater forest fragmentation. For example, in Puerto Rico, where human pressure is greatest among our study areas, forest fragmentation indices show smaller mean patch area, higher patch density, and less core area (Table 3). Severe tropical forest destruction has been widely documented $(33,34)$, particularly in dry tropical forests $(23,35)$. On the other hand, the results suggest the picture is more complicated than might be attributed to human population pressure alone. Indicators of fragmentation were found to be greater in the dry environments compared to the moist environments along the climatic gradient. The number of patches and patch density were greater in the dry study areas

Table 3. Results of the landscape-level metrics $(\mathrm{A})$ and the means and standard errors of the patch-level metrics, the Kruskal-Wallis chi-square test results, and their significance values $(B)$ per study area.

\begin{tabular}{|c|c|c|c|c|c|c|c|c|}
\hline & BO-DRY & BO-MOIST & TE-DRY & TE-MOIST & TR-DRY & TR-MOIST & $\begin{array}{l}\text { Chi-squared } \\
(\text { d.f. }=5)\end{array}$ & p value \\
\hline \multicolumn{9}{|c|}{ A. Landscape-level metrics } \\
\hline TA (ha) & 44504 & 38178 & 43837 & 44347 & 41033 & 34077 & & \\
\hline FA (ha) & 30583 & 29093 & 23959 & 28421 & 16689 & 22569 & & \\
\hline PFOR (\%) & 67.9 & 64.5 & 53.2 & 63.1 & 37.0 & 50.1 & & \\
\hline NP & 133 & 62 & 129 & 116 & 342 & 172 & & \\
\hline PD & 0.30 & 0.14 & 0.29 & 0.26 & 0.76 & 0.38 & & \\
\hline $\mathrm{TE}(\mathrm{km})$ & 1445 & 1753 & 1630 & 1615 & 1719 & 1365 & & \\
\hline REL & 47.3 & 60.2 & 68.0 & 56.8 & 103.0 & 60.5 & & \\
\hline \multicolumn{9}{|c|}{ B. Patch-level metrics } \\
\hline MPA & $230.0(159.6)$ & $469.2(320.1)$ & $185.7(149.8)$ & $245.0(215.6)$ & $48.8(20.7)$ & $131.2(105.0)$ & 65.136 & $<0.001$ \\
\hline PAR & $425.9(19.7)$ & $425.9(40.7)$ & $293.5(14.6)$ & $393.2(19.9)$ & $395.1(10.4)$ & $418.0(29.4)$ & 38.910 & $<0.001$ \\
\hline PROX & $28678(5,142)$ & $57920(1,0163)$ & $11102(3,550)$ & 34336 (6116) & 4005 (599) & $24016(3550)$ & 39.198 & $<0.001$ \\
\hline CORE & $594.3(438.5)$ & $647.9(434.5)$ & 216.3 (198.2) & $508.2(481.8)$ & $99.3(49.0)$ & 224.1 (191.8) & 9.381 & 0.095 \\
\hline
\end{tabular}


compared to the moist study areas in the same climatic region, while the percentage forested area and the mean patch area were smaller. However, forest canopy structure is also naturally more open in drier forest types, which is likely confounding these results aimed at isolating the human forces of fragmentation.

The increased influence of historic fires on drier forested ecosystems also may be contributing to fragmentation. This is a difficult factor to tease apart, as ignitions may be caused by lightning or by humans. The former cause is much more likely in Alaska, while in Puerto Rico, fires were virtually nonexistent prior to human settlement $(23,36)$. Introductions of exotic African grasses are causing the development of cyclic fires in the seasonally dry forest of the TR-DRY area, which may also be contributing to greater fragmentation. Our results support other studies $(23,35)$ that have shown the dry tropical forest ecosystem is particularly fragmented and threatened or endangered. Restoration of less-fragmented dry forest ecosystems may be hindered by the persistence of frequent fires in the grass sward encroaching upon forest edges, often along roads where human ignitions are more likely.

The methods presented in this study represent a way to characterize fragmented forest landscapes across different forest ecosystems using a consistent image data source, processing, and analysis approach. Others have demonstrated the limitations of purely pixel-based image analysis approaches $(14,37)$. Classification of image pixels often results in a "salt and pepper" effect because many pixels are below the minimum mapping unit (MMU) size of interest and which would inflate the number of patches, increase edge length, and have otherwise undesirable consequences on the patch metrics (38). The "salt and pepper" effect is often removed by passing moving windows (such as pixel median or majority filters) over the classified image (39) or establishment of an MMU (40). By first segmenting and thereafter classifying the images, we could avoid the problems caused by single-pixel classification units.

Despite eCognition's capability to delineated discrete units representing landscape pattern, more research is necessary to determine how the procedure works for different types of imagery on different types of edges. Remote-sensing imagery with higher spatial resolution (27) or multidate image delineation $(14,41)$ has the ability to more precisely locate an edge in the field. Further research could focus on the detectability of different types of edges and their relationships to different processes, such as fragmentation.

Besides comparing study areas, landscape metrics can be used to parameterize models and perform risk assessment over larger landscapes. For instance, wildland fire prevention has to deal with the increased complexity of the urban-wildland interface (42; 2007 Caribbean Fire Ecology and Management Symposium outcome). The total edge (TE) calculated exemplifies a metric that could be used as an index of the amount of urban-wildland interface and perhaps as a measure of fire risk. Often these borders are sensitive locations for forested ecosystems that are vulnerable to invasive species and anthropogenic disturbance. The metrics employed in this study could improve our understanding of the dynamic wildland-urban interface (WUI) across fragmented landscapes.

\section{CONCLUSION}

As might be expected, landscapes with higher population and road density are more fragmented. In addition, our results indicate that landscapes in drier climate have a higher degree of fragmentation as compared to their moister counterparts in the same climatic region. Drier climates produce more dispersed vegetation that can appear more fragmented as characterized by our analysis techniques. Separating the competing influences of land use and climate on the patch characteristics of forest fragments is an issue for future research. We encourage further testing of our remote-sensing, image segmentation, and patch analysis methods in other forested landscapes spanning a human population density gradient, or a moisture gradient, within boreal, temperate, or tropical forest types.

\section{References and Notes}

Turner, M.G. 1989. Landscape ecology: the effect of patterns on process. Ann. Rev. Ecol. Syst. 20, 171-197.

Turner, M.G., Gardner, R.H. and O’Neill, R.V. (eds). 2001. Landscape Ecology in Theory and Practice: Pattern and Process. Springer, New York, $401 \mathrm{pp}$.

Ohman, K. and Eriksson, L.O. 1998. The core area concept in forming contiguous area for long-term forest planning. Can. J. Forest. Res. 28, 1032-1039.

. Heilman, G.E., Strittholt, J.R., Slosser, N.C. and Dellasala, D.A. 2002. Fores fragmentation of the conterminous United States: assessing forest intactness through road density and spatial characteristics. BioScience 52, 411-422.

5. Kemper, J., Cowling, R.M., Richardson, D.M., Forsyth, G.G. and McKelly, D.H. 2000 Landscape fragmentation in South Coast Renosterveld, South Africa, in relation to rainfall and topography. Austral. Ecol. 25, 179-186.

6. Turner, M.G., Pearson, S.M., Bolstad, P. and Wear, D.N. 2003. Effects of land-cover change on spatial pattern of forest communities in the Southern Appalachian Mountains (USA). Landscape Ecol. 18, 449-464.

7. Zhu, M., Jiang, N., Li, J., Xu, J. and Fan, Y. 2006. The effects of sensor spatial resolution and changing grain size on fragmentation indices in urban landscape. Int.J. Remote Sensing 27, 4791-4805.

Murcia, C. 1995. Edge effects in fragmented forests - implications for conservation. Trends Ecol. Evol. 10, 58-62.

Fahrig, L. 2003. Effects of habitat fragmentation on biodiversity. Ann. Rev. Ecol., Evol. Syst. 34, 487-515.

10. Cochrane, M.A. and Laurance, W.F. Synergisms among fire, land use, and climate change in the Amazon. Ambio. 37, 522-527.

Cochrane, M.A. and Laurance, W.F. 2002. Fire as a large-scale edge effect in Amazonian forests. J. Trop. Ecol. 18, 311-325.

12. Hudak, A.T., Morgan, P., Bobbitt, M. and Lentile, L. 2007. Characterizing stand replacing harvest and fire disturbance patches in a forested landscape: a case study from Cooney Ridge, Montana. In: Understanding Forest Disturbance and Spatial Pattern, Wulder, M.A. and Franklin, S.E. (ed). Taylor and Francis Group, Boca Raton, Flordia, $246 \mathrm{pp}$.

13. Cohen, W. B and Goward, S.N. 2004. Landsat's role in ecological applications of remote sensing. Bioscience 54, 535-545.

4. Desclée, B., Bogaert, P. and Defourny, P. 2006. Forest change detection by statistical object-based method. Remote Sens. Environ. 102, 1-11.

15. Flanders, D., Hall-Beyer, M. and Pereverzoff, J. 2003. Preliminary evaluation of eCognition object-based software for cut block delineation and feature extraction. Can J. Remote Sens. 29, 441-452.

16. Jobin, B., Labrecque, S., Grenier, M. and Falardeau, G. 2008. Object-based classification as an alternative approach to the traditional pixel-based classification to identify potential habitat of the Grasshopper Sparrow. Environ. Manage 41, 20-31.

17. Baatz, M. and Schäpe, A. 2000. Multiresolution segmentation: an optimizing approach for high quality multi-scale image segmentation. In: Angewandte Geographisch Informationsverarbeitung, XII. Strobl, J. and Blaschke, T. (eds). Wichmann, Heidelberg, pp. $12-23$.

Definiens. 2004. eCognition professional 4.0. (http://www.definiens.com)

19. McGarigal, K., Cushman, S.A., Neel, M.C. and Ene, E. 2002. FRAGSTATS: spatial pattern analysis program for categorical maps. Computer software program. (www. umass.edu/landeco/research/fragstats/fragstats.html)

20. Apan, A.A., Raine, S.R. and Paterson, M.S. 2002. Mapping and analysis of changes in the riparian landscape structure of the Lockyer Valley catchment, Queensland. Austral. Landscape Urban. Plan. 59, 43-57.

21. Di Orio, A.P., Callas, R. and Schaefer, R.J. 2005. Forty-eight year decline and ragmentation of aspen (Populus tremuloides) in the South Warner Mountains of California. Forest Ecol. Manage. 206, 307-313.

22. Cain, D.H., Riitters, K. and Orvis, K. 1997. A multi-scale analysis of landscape statistics, Landscape Ecol. 12, 199-212.

23. Murphy, P.G. and Lugo, A.E. 1995. Dry forests of Central America and the Caribbean islands. In: Seasonally Dry Tropical Forests, Bullock, S., Mooney, H.A. and Medina, E. islands. In: Seasonally Dry Tropical Forests, Bullock, S., M
(eds). Cambridge University Press, Cambridge, pp. 9-34.

24. Chavez, P S. Jr 1996. Image-based atmospheric corrections-revisited and improved. Photogramm. Engin. Rem. Sens. 62, 1025-1036.

25. Steinnocher, K. 1999. Adaptive fusion of multisource raster data applying filter techniques. Int. Arch. Photogramm. Rem. Sens. 32, 108-115.

26. Martinuzzi, S., Gould, W.A. and González-Ramos, O.M. 2007. Creating Cloud-Fre Landsat ETM+ Data Sets in Tropical Landscapes: Cloud and Cloud-Shadow Removal. International Institute of Tropical Forestry Report IITF-GTR 32.USDA Forest Service, Rio Piedras, $12 \mathrm{pp}$

27. Davidson, A., Hudak, A.T., Evans, J.S., Gould, W.A. and González, G. 2008. Multiresolution image segmentation for delineation of forest landscape units. (In review).

Gustafson, E.J and Crow, T. R. 1998. Simulating spatial and temporal context of forest management using hypothetical landscapes. Environ. Manage. 22, 777-787.

29. Siegert, N.W. and McCullough, D.G. 2003. Colonization of Scots, red, and jack pine logs by Tomicus piniperda (Coleoptera:Scolytidae) in Michigan pine stands. Can. J. For. Res. 33, 2238-2244

30. Crist, E P 1985. A Thematic Mapper tasseled cap equivalent for reflectance factor data. Remote Sens. Environ. 17, 301-306.

31. Ott, L. and Longnecker, M. 2001. An Introduction to Statistical Methods and Data Analysis. Duxbury, Pacific Grove, California, $1152 \mathrm{pp}$.

. R Development Core Team. 2004. R: a language and environment for statistica computing. R foundation for statistical computing. (http://www.r-project.org)

33. Skole, D. and Tucker, C. 1993. Tropical deforestation and habitat fragmentation in the Amazon: satellite data from 1978 to 1988. Science 260, 1905-1910.

34. Southworth, J., Munroe, D. and Nagendra, H. 2004. Land cover change and landscape fragmentation-comparing the utility of continuous and discrete analyses for a wester Honduras region. Agr. Ecosyst. Environ. 101, 185-205.

35. Maass, J.M. 1995. Conversion of tropical dry forests to pasture and agriculture. In: Seasonally Dry Tropical Forests, Bullock, S., Mooney, H.A. and Medina, E. (eds) Cambridge University Press, Cambridge, pp. 399-422.

36. Burney, D.A., Burney, L.P. and McPhee, R.D.E. 1994. Holocene charcoal stratigraph from Laguna Tortuguero, Puerto Rico, and the timing of human arrival on the island. $J$. Archaeol. Sci. 21, 273-281.

37. Lobo, A. 1997. Image segmentation and discriminant analysis for the identification of land cover units in ecology. IEEE Trans. Geosci. Rem. 35, 1136-1148. 
38. Saura, S. 2002. Effects of minimum mapping unit on land cover data spatial configuration and composition. Int. J. Rem. Sens. 23, 4853-4880.

39. Lillesand, T.M. and Kiefer, R.W. 2000. Remote Sensing and Image Interpretation. John Wiley and Sons, New York, $724 \mathrm{pp}$

40. Gergel, S.A. 2007. New directions in landscape pattern analysis and linkages with remote sensing. In: Understanding Forest Disturbance and Spatial Pattern, Wulder, M.A. and Franklin, S.E. (eds). Taylor and Francis Group, Boca Raton, Florida, 246 pp.

41. Lhermitte, S., Verbesselt, J., Jonckheere, I., Nackaerts, K., van Aardt, J.A.N., Verstraeten, W.W. and Coppin, P. 2008. Hierarchical image segmentation based on Verstraeten, W.W. and Coppin, P. 2008. Hierarchical image segment
similarity of NDVI time series. Remote Sens. Environ. 112, 506-521.
42. Radeloff, V.C., Hammer, R.B., Stewart, S.I., Fried, J.S., Holcomb, S.S. and McKeefry, J.F. 2005. The wildland-urban interface in the United States. Ecol. Appl. 15, 799-805.

43. Acknowledgments: This research was funded by the Joint Fire Science Program project entitled, "Landscape Fragmentation and Forest Fuel Accumulation: Effects of Fragment Size, Age, and Climate" (JFSP Project Number: 01-1-3-37). The work by Arjan Meddens was also made possible by the Rocky Mountain Research Station, Experience International, and the University of Waninan. Research Internation International Institule or Tropical Forestry is done in collaboration with the University helpful comments.
Arjan Meddens is currently a PhD student at the University of Idaho, and his PhD project involves quantifying tree mortality from a mountain pine beetle infestation in the Sawtooth Mountains in Idaho using LiDAR remote sensing. His address: Department of Geography, University of Idaho, PO Box, 443021, McClure Hall 203, Moscow, ID 83844-3021, USA.

E-mail: arjan.meddens@vandals.uidaho.edu

Andrew T. Hudak is a research forester specializing in landscape-level applications of remote sensing for improved ecosystem management at the USDA Forest Service, Rocky Mountain Research Station. His address: USDA Forest Service, Rocky Mountain Research Station, 1221 South Main Street, Moscow, ID 83843, USA.

E-mail: ahudak@fs.fed.us

Jeffrey S. Evans is a landscape ecologist with the USDA Forest Service, Rocky Mountain Research Station. His current research includes forest structural modeling using LiDAR, spatial uncertainty, and landscape genetics. His address: USDA Forest Service, Rocky Mountain Research Station, 1221 South Main
Street, Moscow, ID 83843, USA.

E-mail: jevans02@fs.fed.us

William Gould is a landscape ecologist investigating biodiversity, conservation, land cover, and land-use patterns and processes in tropical, temperate, and arctic biomes. He leads the Puerto Rico and US Virgin Islands Gap Analysis Programs and the International Institute of Tropical Forestry GIS and Remote Sensing Laboratory. His address: USDA Forest Service, International Institute of Tropical Forestry, 1201 Calle Ceiba, Río Piedras, 00926-1115, Puerto Rico.

E-mail: wgould@fs.fed.us

Grizelle González is a research ecologist at USDA Forest Service, International Institute of Tropical Forestry and adjunct faculty to the Department of Biology, University of Puerto Rico, Río Piedras Campus. Her interests are soil ecology and biology and terrestrial biogeochemistry. Her address: USDA Forest Service, International Institute of Tropical Forestry, 1201 Calle Ceiba, Río Piedras, 00926-1115, Puerto Rico.

E-mail: ggonzalez@fs.fed.us 